\title{
Epidemiological, humanistic, and economic burden of illness of lower limb spasticity in adults: a systematic review
}

This article was published in the following Dove Press journal:

Neuropsychiatric Disease and Treatment

23 January 2014

Number of times this article has been viewed

\author{
Alison Martin' \\ Seye Abogunrin' \\ Hannah Kurth ${ }^{2}$ \\ Jerome Dinet ${ }^{2}$ \\ 'Evidera, London, UK; ${ }^{2}$ Ipsen, Boulogne \\ Billancourt Cedex, France
}

Background: The purpose of this study was to investigate the epidemiological, humanistic, and economic burden of illness associated with adult lower limb spasticity (LLS) and its complications.

Methods: A systematic search of MEDLINE and EMBASE identified 23 studies published between January 2002 and October 2012 that assessed the epidemiology, impact, and resource use associated with LLS. A hand-search of four neurology conferences identified abstracts published between 2010 and 2012 .

Results: LLS was found to occur in one third of adults after stroke, half to two thirds with multiple sclerosis, and three quarters with cerebral palsy. LLS limits mobility and reduces quality of life. No clear association was found between LLS and occurrence of pain, development of contractures, or risk of falls.

Conclusion: The evidence on the burden of LLS and its complications is surprisingly limited given the condition's high prevalence among adults with common disorders, such as stroke. Further research is needed to clarify the impact of LLS, including the likelihood of thrombosis in spastic lower limbs. The dearth of high-quality evidence for LLS suggests a lack of awareness of, and interest in, the problem, and therefore, the unmet need among patients and their carers.

Keywords: muscle spasticity, cost of illness, complications, quality of life

\section{Introduction}

Lower limb spasticity (LLS) results from a lack of upper motor neuron inhibitory control over spinal-reflex contraction of muscles around the hip, knee, ankle, and foot. Typically, the condition is found in patients with injury to the brain or spinal cord from cerebral palsy, stroke, or trauma, or where demyelinated upper motor neurons fail to function in multiple sclerosis. ${ }^{1,2}$ The incidence and prevalence of these conditions varies geographically, but various reviews of the literature and other data have led to estimates of the range of people likely to be affected, and these are summarized in Table 1.

Various factors have been associated with an increased likelihood of spasticity of any muscle, for example, more severe paralysis immediately after a stroke, ${ }^{2-6}$ younger age at time of stroke; ${ }^{5,7}$ and a history of smoking. ${ }^{2,3}$ However, we found no evidence that these or any other factors are specifically predictive of LLS.

Spasticity of the upper limbs can be particularly disabling by impairing manual dexterity, and has been the focus of much research. LLS, by adversely affecting mobility and balance, may also have a substantial negative impact on independence and add to the burden on carers. However, there is relatively little published research
Correspondence: Alison Martin

Evidera, 26-28 Hammersmith Grove,

London W6 7HA, UK

Tel +4402088349586

Fax +4402088340101

Email alison.martin@evidera.com
Dovepress

http://dx.doi.org/10.21 47/NDT.S53913
Neuropsychiatric Disease and Treatment 2014:10 III-122

(c) (1) (2) ( 2014 Martin et al. This work is published by Dove Medical Press Limited, and licensed under Creative Commons Attribution - Non Commercial (unported, v3.0) 
Table I Reported incidence and prevalence of conditions associated with lower limb spasticity

\begin{tabular}{|c|c|c|c|}
\hline Condition & $\begin{array}{l}\text { Annual } \\
\text { incidence }\end{array}$ & Prevalence & References \\
\hline Stroke & $\begin{array}{l}30-485 \text { per } \\
100,000\end{array}$ & $\begin{array}{l}40-600 \\
\text { per } 100,000\end{array}$ & 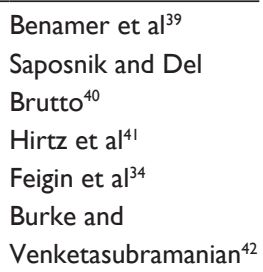 \\
\hline $\begin{array}{l}\text { Multiple } \\
\text { sclerosis }\end{array}$ & - & $\begin{array}{l}2-350 \\
\text { per100,000 }\end{array}$ & $\begin{array}{l}\text { Cristiano et } \mathrm{al}^{43} \\
\text { Cooper et } \mathrm{al}^{44} \\
\text { Poppe et } \mathrm{al}^{45} \\
\text { Hirtz et } \mathrm{al}^{41}\end{array}$ \\
\hline $\begin{array}{l}\text { Cerebral } \\
\text { palsy }\end{array}$ & - & $\begin{array}{l}240-360 \text { per } \\
100,000\end{array}$ & Yeargin-Allsopp et $\mathrm{al}^{46}$ \\
\hline $\begin{array}{l}\text { Traumatic } \\
\text { brain injury }\end{array}$ & $\begin{array}{l}100-235 \\
\text { per } 100,000\end{array}$ & - & $\begin{array}{l}\text { Hirtz et } \mathrm{al}^{41} \\
\text { Tagliaferri et } \mathrm{al}^{47}\end{array}$ \\
\hline $\begin{array}{l}\text { Spinal cord } \\
\text { injury }\end{array}$ & $\begin{array}{l}0.2-8 \text { per } \\
100,000\end{array}$ & $\begin{array}{l}22-90 \text { per } \\
100,000\end{array}$ & $\begin{array}{l}\text { Hagen et } \mathrm{al}^{48} \\
\text { Wyndaele et } \mathrm{al}^{49} \\
\text { Cripps et } \mathrm{al}^{36} \\
\text { Hirtz et } \mathrm{al}^{41} \\
\text { Devivo }^{37}\end{array}$ \\
\hline
\end{tabular}

on the epidemiology and impact of LLS itself. For example, although various systematic reviews have investigated the incidence and prevalence of the underlying pathologies of LLS, some of which are cited in Table 1, we found only one review on the prevalence of LLS following stroke. ${ }^{8}$ This review found no consensus among the included studies regarding the proportion of patients developing LLS or the relationship between LLS and motor disabilities after stroke. A second, recently published systematic review focused on the pathophysiology and onset of spasticity after stroke, and concluded that the association between spasticity and contractures was still unclear, and that a greater understanding of risk factors for spasticity after stroke was needed. ${ }^{3}$

We have found no other systematic reviews on the prevalence of LLS specifically; on the epidemiology of LLS in conditions other than stroke; or on the impact of LLS on patients and carers. We therefore conducted this systematic review to identify studies specifically on the epidemiological, humanistic (eg, quality of life), and economic burden associated with adult LLS, with the aim of describing and quantifying the size of the problem and its impact on patients and carers.

\section{Methods}

This systematic review was conducted in accordance with guidelines from the Preferred Reporting Items for Systematic Reviews and Meta-Analyses (PRISMA, reported at http://www.prisma-statement.org/statement.htm). We aimed to use a rigorous and transparent methodology to minimize bias in the selection of relevant studies, while also restricting the scope of the review to focus on the most recent evidence that best reflects current disease management and clinical relevance.

\section{Data sources}

We systematically reviewed the literature indexed in MEDLINE and EMBASE and published in the last 10 years (October 2002 to October 2012) relating to the epidemiological, humanistic, and economic burden associated with LLS in adults. The search strategy used is reported in full in the Supplementary materials, and was constructed from search terms relating to quality of life, utilities, burden, and other outcomes; OR cost and resource use; OR incidence, prevalence, and unmet need; combined with terms for spasticity AND the lower limb AND the main underlying pathologies associated with LLS. The search was subsequently narrowed by excluding studies relevant only to children and narrative reviews.

We also manually searched the websites of the World Federation for Neurorehabilitation, the World Stroke Congress, the World Federation of Neurology, and the American Neurological Association/Association of British Neurologists for relevant conference abstracts published in 2010-2012.

\section{Study selection}

The first 100 abstracts were screened independently by two researchers and any disagreements resolved by discussion. Each abstract was then screened by one researcher and included studies checked by another researcher. Inclusion criteria for study selection were primary research and systematic reviews relevant to adults with LLS from any cause, reporting epidemiological, quality of life, or economic outcomes, and published in English between 2002 and 2012. Outcomes related to the incidence or prevalence of LLS; health or social problems and comorbidities associated with LLS; treatment patterns for LLS; quality of life, utilities, and other patient-reported outcomes; costs and resource use for people with LLS; and burden on carers and society from LLS. The inclusion and exclusion criteria are reported in full in the Supplementary materials.

The full texts were retrieved for all studies that definitely or possibly met the inclusion criteria on abstract screening. Full-text screening used the same inclusion criteria as abstract screening, but focused more precisely on identifying studies with clinically relevant outcomes. Full-text screening was conducted independently by two researchers and disagreements were resolved by discussion. 


\section{Data extraction}

Data from the included studies were extracted into a pre-agreed template in MS Word ${ }^{\circledR}$ by one researcher and all data extraction tables were checked by a second researcher. No statistical analysis was planned but the results were synthesized narratively to identify common themes and gaps in the evidence.

\section{Results}

The database search of MEDLINE and EMBASE identified 3,106 citations, of which 912 were duplicates, leaving 2,194 unique citations for screening. We identified many studies that reported on spasticity in general, but the evidence base on LLS specifically was much smaller. A total of 52 articles were identified as potentially meeting the inclusion criteria and were retrieved as full texts, and 23 of these were subsequently included in the review. The search for gray literature yielded one additional study, making a total of 24 that were synthesized in the final review (Figure 1).

The 24 studies included in our systematic review all described primary research on the epidemiological, humanistic, and economic burden, including disease pathways and treatment patterns of LLS in adults. Most of these studies used observational cohort and cross-sectional methodologies and reported epidemiologic outcomes, with some reporting multiple outcomes. Most reported on the epidemiology of LLS, with only two reporting on quality of life and one on costs of treatment. The study characteristics are summarized in Table 2.

\section{Instruments used to assess spasticity}

There was considerable variation between studies on the instruments used to measure LLS. The Modified Ashworth Scale ${ }^{9}$ was the most widely used overall, but was applied only in patients with stroke and multiple sclerosis. The Ashworth Scale $^{10}$ and the Tardieu Scale ${ }^{11}$ were the only other instruments reported as being used in more than one study.

\section{Epidemiologic burden}

Twelve studies reported on the prevalence of LLS in cohorts with a particular underlying disease. These are summarized in

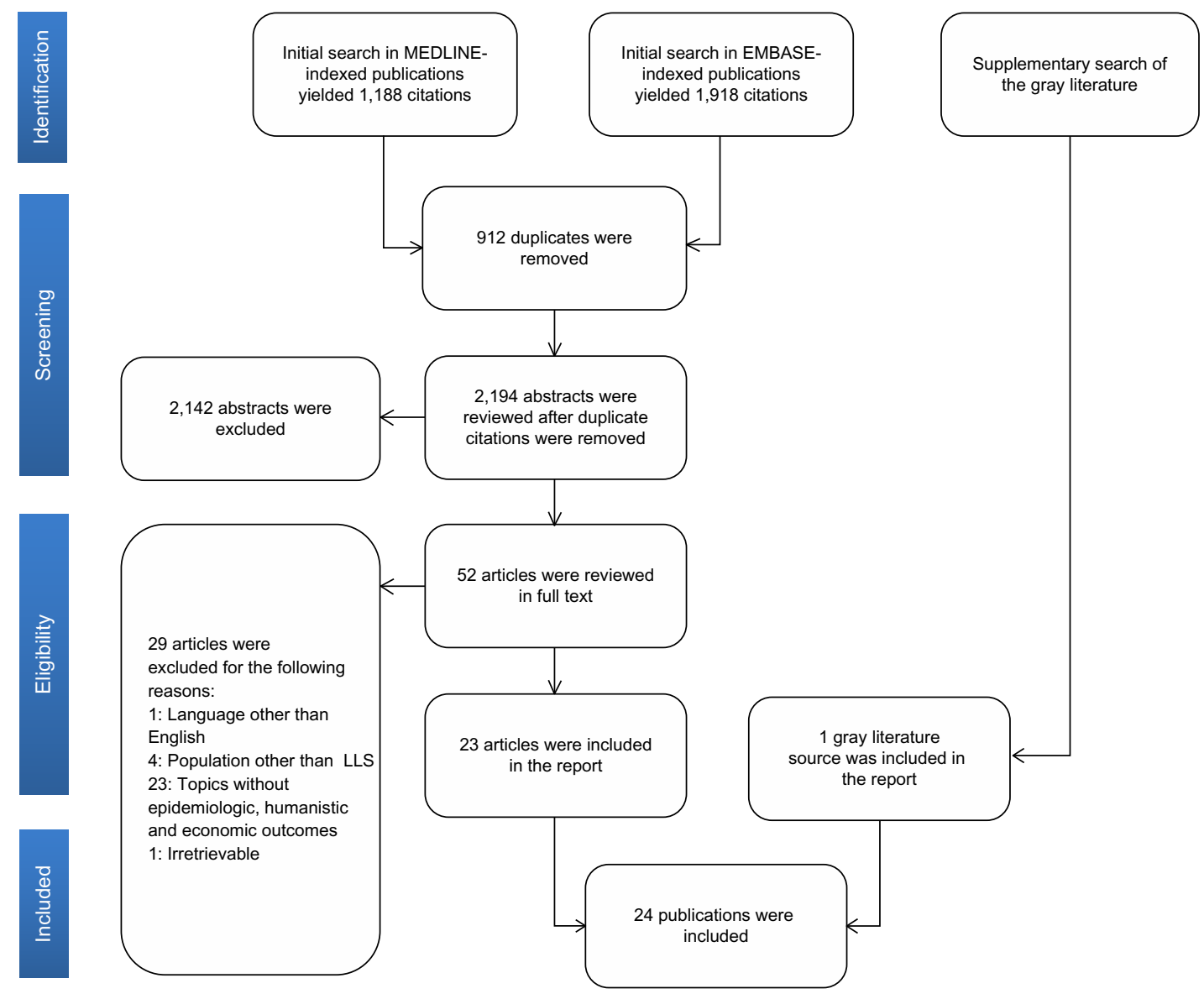

Figure I Flow of literature.

Abbreviation: LLS, lower limb spasticity. 
Table 2 Characteristics of studies included in this review

\begin{tabular}{|c|c|c|c|c|}
\hline Reference & Underlying pathology & Country & Participants (n) & Focus of study \\
\hline Marciniak et $\mathrm{al}^{22}$ & Cerebral palsy & Not reported & 91 & Complications \\
\hline Noonan et $\mathrm{al}^{21}$ & Cerebral palsy & USA & 77 & Prevalence, complications \\
\hline Burbaud et $\mathrm{al}^{29}$ & $\begin{array}{l}\text { Lower limb spasticity } \\
\text { of any cause }\end{array}$ & France & 870 & $\begin{array}{l}\text { Treatment patterns, cost of } \\
\text { treatment }\end{array}$ \\
\hline Marchese et $\mathrm{al}^{31}$ & $\begin{array}{l}\text { Lower limb spasticity } \\
\text { of any cause }\end{array}$ & $\begin{array}{l}\text { France, Germany, } \\
\text { Greece, Sweden, UK }\end{array}$ & 127 & Treatment patterns \\
\hline Zamli and Xiong ${ }^{32}$ & $\begin{array}{l}\text { Lower limb spasticity } \\
\text { of any cause }\end{array}$ & New Zealand & 74 & Treatment patterns \\
\hline Hoang et $\mathrm{al}^{14}$ & Multiple sclerosis & Australia & 156 & Prevalence \\
\hline Nogueira et $\mathrm{al}^{33}$ & Multiple sclerosis & Brazil & 61 & Quality of life \\
\hline Salci et al $^{16}$ & Multiple sclerosis & Turkey & 51 & Prevalence \\
\hline Marcotte et al ${ }^{15}$ & Multiple sclerosis & USA & 17 & Prevalence, complications \\
\hline Sosnoff et al ${ }^{17}$ & Multiple sclerosis & USA & 34 & Prevalence, complications \\
\hline Wagner and $\mathrm{Kremer}^{18}$ & Multiple sclerosis & USA & 42 & Prevalence \\
\hline Singer et $\mathrm{al}^{20}$ & Primary lateral sclerosis & USA & 25 & Prevalence \\
\hline Diong et $\mathrm{al}^{25}$ & Spinal cord injury & Australia & 80 & Complications \\
\hline Voerman et $\mathrm{al}^{24}$ & Spinal cord injury & The Netherlands & 19 & Complications, quality of life \\
\hline Kwah et $\mathrm{al}^{26}$ & Stroke & Australia & 165 & Complications \\
\hline Pang et $\mathrm{al}^{23}$ & Stroke & Canada & 39 & Complications \\
\hline Laurent et $\mathrm{al}^{27}$ & Stroke & France & 39 & Complications \\
\hline Urban et $\mathrm{al}^{6}$ & Stroke & Germany & 211 & Prevalence \\
\hline $\mathrm{Hara}^{28}$ & Stroke & Japan & 296 & Complications \\
\hline Dajpratham et al ${ }^{12}$ & Stroke & Thailand & 327 & Prevalence, treatment patterns \\
\hline Soyuer and Ozturk ${ }^{13}$ & Stroke & Turkey & 100 & Prevalence, complications \\
\hline Leathley et $\mathrm{al}^{3}$ & Stroke & UK & 106 & Prevalence, predictive factors \\
\hline Esquenazi et $\mathrm{al}^{30}$ & Stroke and traumatic brain injury & USA & 487 & Treatment patterns \\
\hline Singer et al $^{19}$ & Traumatic brain injury & Australia & 105 & Prevalence, complications \\
\hline
\end{tabular}

Table 3. No study was identified that reported on the annual incidence of LLS from any cause.

Although the evidence is patchy, there was general agreement between studies that around one-third of patients with stroke develop LLS affecting the hip, knee, and/or ankle. ${ }^{3,6,12,13}$ The prevalence of severe spasticity, defined as Modified Ashworth Scale scores $\geq 3$, was below $6 \%$ in each of the two studies that reported on this outcome, although both of these assessed patients in the first few months after stroke and so may underestimate long-term severity.

The prevalence of LLS in patients with multiple sclerosis was around $40 \%-50 \%$ in any muscle group studied, ${ }^{14-18}$ with around two thirds of patients having spasticity in any part of the lower limb. ${ }^{14}$ Bilateral spasticity may be more common than unilateral LLS, although this suggestion is based on data from one small study. ${ }^{17}$ No studies reported on the severity of spasticity in patients with multiple sclerosis.

Few data were identified on the prevalence of LLS associated with other upper motor neuron disorders. One in six people with traumatic brain injury had LLS, ${ }^{19}$ while $92 \%$ of a group with primary lateral sclerosis developed the condition. ${ }^{20}$ The prevalence of LLS was not reported in adults with cerebral palsy, but one study found that $25 \%$ of patients with cerebral palsy had mild, $56 \%$ had moderate, and $19 \%$ had severe spasticity in the lower limbs. ${ }^{21}$ These data on the prevalence of LLS in different underlying pathologies are summarized in Table 3.

These epidemiologic studies used different instruments to measure LLS, and tended to assess spasticity in different muscle groups, making it hard to generalize about the scale of the problem. However, it seems likely that LLS is a common problem in people with upper motor neuron disorders. The lack of a consistent approach to detecting and assessing LLS in the studies is of concern, as it suggests that such evaluation may not be a routine part of clinical management and, therefore, that patients with LLS may not be receiving appropriate treatment for their spasticity.

\section{Impairment in LLS}

We identified 12 studies that reported on complications associated with LLS. These are summarized in Table 4. LLS was consistently associated with limited mobility and motor function in patients with multiple sclerosis, ${ }^{15,17}$ cerebral palsy, ${ }^{22}$ and stroke. ${ }^{23}$ It was significantly associated with impairment as measured by the Expanded Disability Status Scale score, ${ }^{17}$ with some limitations on driving ability in patients with 
Table 3 Prevalence of LLS in different conditions

\begin{tabular}{|c|c|c|c|c|c|}
\hline Study & Country & $\mathbf{n}$ & Muscle groups & Instrument & Prevalence of LLS \\
\hline \multicolumn{6}{|l|}{ Stroke } \\
\hline Dajpratham et al' ${ }^{12}$ & Thailand & 327 & Knee flexors & MAS & $37 \%$ \\
\hline Leathley et $\mathrm{al}^{3}$ & UK & 106 & Hip and knee & TAS, TASMAX & $28 \%-31 \%$ \\
\hline Leathley et $\mathrm{a}^{3}$ & UK & 106 & Ankle & TAS, TASMAX & $32 \%$ \\
\hline Urban et al ${ }^{6}$ & Germany & 211 & Any LL & MAS & $35 \%$ \\
\hline Soyuer and Ozturk ${ }^{13}$ & Turkey & 100 & Any LL & AS & $29 \%$ \\
\hline \multicolumn{6}{|l|}{ Multiple sclerosis } \\
\hline Hoang et $\mathrm{al}^{14}$ & Australia & 156 & Any LLS & Tardieu Scale & $66 \%$ \\
\hline Sosnoff et al ${ }^{17}$ & USA & 34 & $\begin{array}{l}\text { Gastrocnemius-soleus } \\
\text { (ankle flexor) }\end{array}$ & MAS & $44 \%$ \\
\hline Wagner and Kremer ${ }^{18}$ & USA & 42 & Ankle flexors & $\begin{array}{l}\text { MAS, ISM, } \\
\text { dynamometer }\end{array}$ & $69 \%$ \\
\hline Hoang et $\mathrm{al}^{14}$ & Australia & 156 & Ankle flexors & Tardieu Scale & $48 \%$ \\
\hline Marcotte et $\mathrm{al}^{15}$ & USA & 17 & Knee & MAS & $47 \%$ \\
\hline Hoang et $\mathrm{al}^{14}$ & Australia & 156 & Knee extensors & Tardieu Scale & $41 \%$ \\
\hline Salci et $\mathrm{al}^{16}$ & Turkey & 51 & Knee & MAS & Mean score 4.33 \\
\hline \multicolumn{6}{|l|}{ Cerebral palsy } \\
\hline Noonan et $\mathrm{al}^{21}$ & USA & 77 & Knee & AS & $\begin{array}{l}25 \% \text { none or mild } \\
56 \% \text { moderate } \\
19 \% \text { severe }\end{array}$ \\
\hline \multicolumn{6}{|l|}{ Traumatic brain injury } \\
\hline Singer et $\mathrm{al}^{19}$ & Australia & 105 & Any LL & AS & $13 \%$ \\
\hline \multicolumn{6}{|l|}{ Primary lateral sclerosis } \\
\hline Singer et $\mathrm{al}^{20}$ & USA & 25 & Any LL & NR & $92 \%$ \\
\hline
\end{tabular}

Abbreviations: MAS, Modified Ashworth Scale; TAS, Tone Assessment Scale; TASMAX, Tone Assessment Scale, Maximum score at any one joint; AS, Ashworth Scale; NR, not reported; LL, lower limb; LLS, lower limb spasticity; ISM, instrumented spasticity measure.

multiple sclerosis, ${ }^{15}$ and with slower time to climb stairs in patients with stroke. ${ }^{22}$ LLS was also a reason for adults with cerebral palsy to stop walking. ${ }^{22}$

The evidence was contradictory on whether LLS was associated with pain. Severe knee muscle spasticity was associated with hip pain in a study involving 77 patients with cerebral palsy, and was greater among those with more severe spasticity. ${ }^{21}$ A second, smaller study found no association between self-reported spasticity and pain in patients with spinal cord injury. ${ }^{24}$

\section{Complications of LLS}

There is clearly an association between spasticity and the development of contractures. However, none of the four studies that reported on the occurrence of contractures in patients with LLS found that the two problems were independently associated after adjusting for other risk factors. ${ }^{20,25-27}$ Three of the four studies were conducted in Australia and one in France, and the included patients had LLS resulting from stroke or transient ischemic attack, or injuries to the brain or spinal cord. Based on this rather limited evidence, it seems possible that one or more other confounding factors may increase the likelihood of both spasticity and contracture, in particular, in people with spinal cord injury or stroke. For example, one of the studies found a significant association between dystonia and contractures after brain injury. ${ }^{20}$ It would be interesting to determine whether effective early management of spasticity can prevent the development of contractures, regardless of the underlying causative mechanisms.

Table 4 Summary of risk of complications associated with lower limb spasticity in different underlying pathologies

\begin{tabular}{|c|c|c|c|c|c|}
\hline Underlying pathology & Contractures & Limited mobility & Falls & Deep vein thrombosis & Pain \\
\hline Cerebral palsy & & Increased risk ${ }^{22}$ & & & $\begin{array}{l}\text { Knee spasticity increases } \\
\text { risk of hip pain }{ }^{21}\end{array}$ \\
\hline Multiple sclerosis & & Increased risk ${ }^{15,17}$ & & & \\
\hline Spinal cord injury & No increased risk ${ }^{25}$ & & & & No association ${ }^{24}$ \\
\hline Stroke & $\begin{array}{l}\text { Contradictory } \\
\text { evidence on risk }{ }^{26,27}\end{array}$ & Increased risk ${ }^{23}$ & $\begin{array}{l}\text { Contradictory } \\
\text { evidence on risk }{ }^{13,23}\end{array}$ & $\begin{array}{l}\text { Increased risk in } \\
\text { spastic calf }{ }^{28}\end{array}$ & \\
\hline Traumatic brain injury & No increased risk ${ }^{19}$ & & & & \\
\hline
\end{tabular}


The association between LLS and likelihood of falling was inconsistent: one study of 100 patients with LLS after stroke found a significant increase in this risk with increasing severity of spasticity, ${ }^{13}$ while a study of 39 patients in Canada, also after stroke, found no such association. ${ }^{22}$

Another potential complication of spasticity worthy of further research is deep vein thrombosis, which was found to be 28 times more common in the spastic leg than the normal limb in 296 patients undergoing rehabilitation after ischemic stroke in Japan. ${ }^{28}$

\section{Predictors of LLS}

In one UK study of patients following stroke, greater impairment of daily functioning and early leg weakness were significant predictors of LLS at 12 months. ${ }^{3}$ A history of smoking was also suggested to be a risk factor for more severe spasticity in any muscle group in this study, but no statistical significance was reported for this finding. Overall, the evidence on predictors of spasticity specifically of the lower limb was sparse, and merits further investigation.

\section{Treatment patterns for LLS}

There have been few published reports on how LLS is currently managed. What evidence there is, however, suggests substantial variation across geographical regions and between individual clinicians as to when local therapies such as botulinum toxin injections are used, and which regimens are chosen. ${ }^{12,29-32}$ This review did not set out to determine the comparative effectiveness of interventions for LLS, and it remains unclear whether guidelines, such as those on the use of botulinum toxin, are being adhered to and whether there is significant unmet need from suboptimal care.

\section{Humanistic burden}

Although few studies have been published on humanistic burden (eg, quality of life) associated with LLS, there is a suggestion that the condition is associated with impaired physical and psychologic quality of life. ${ }^{24,33}$ The sparse evidence base means, however, that it is difficult to draw robust conclusions.

\section{Economic burden}

No studies were found on the direct or indirect health or social costs of LLS or on the resources needed to care for people with the condition. Only one study compared costs of treatment for LLS; this was not a randomized study, and the substantial baseline differences between the two treatment groups, which received different botulinum toxin preparations, mean that no useful conclusions can be drawn from this study. ${ }^{29}$

\section{Discussion}

Previous systematic reviews on the prevalence and incidence of the conditions most associated with LLS (summarized in Table 1), combined with our current review which gives insight on the likelihood of LLS associated with these conditions (reported in Table 3), lead us to suggest the following international disease patterns:

- 30-500 per 100,000 population have had a stroke, of whom one third might have LLS

- 2-90 per 100,000 have multiple sclerosis, of whom half to two thirds might have LLS

- 250-360 per 100,000 have cerebral palsy, of whom three quarters might have LLS

- 100-230 per 100,000 each year experience traumatic brain injury, of whom one eighth might have LLS

- 22-180 per 100,000 have spinal cord injury, of whom an unknown proportion might have LLS.

The epidemiologic burden of LLS is therefore high, but may shift over time as the epidemiology of the underlying conditions changes. For example, there is evidence that the prevalence of stroke has fallen in developed countries ${ }^{34}$ but may increase again in the future with ageing of the population. ${ }^{35}$ In the developing world, the prevalence of stroke is increasing as lifestyle changes increase the risk for cardiovascular disease. Similarly, increasing use of motor vehicles in developing countries, such as the People's Republic of China, may lead to an increase in people with LLS following traumatic brain or spinal cord injury, and ageing populations in the West may also be associated with a growing number of elderly patients who experience injuries after falls due to LLS. ${ }^{36,37}$ It is possible that improved survival after predisposing events such as stroke or traumatic brain injury might lead to higher prevalence of LLS in long-term survivors, but we identified no studies that assessed this possibility. Similarly, neurophysiologic and biomechanical parameters may play a changing role in the development of LLS, but assessing these relationships was beyond the scope of our review.

Given the likely high prevalence of LLS internationally, the scarcity of published research on the associated burden of illness is surprising. We have, for example, identified only two prior systematic reviews on the topic, both focusing on patients with stroke. ${ }^{2,8}$ Schinwelski and Slawek ${ }^{8}$ concluded that there was insufficient evidence from published studies to determine the likely prevalence of LLS after stroke. We found only four individual studies assessing this, ${ }^{3,6,12,13}$ but 
all of these reported that approximately one third of patients developed LLS after stroke. The small number of studies is a concern, but the consistency of our prevalence findings gives some reassurance about the credibility of our conclusions.

Ward $^{2}$ also found only a very limited evidence base on predictors of spasticity in any muscle group after stroke, identifying just two studies on the topic, one of which was included in our review. ${ }^{3}$ This review ${ }^{2}$ concluded that patients with more severe disability at baseline were more likely to develop spasticity after a stroke, but that there was uncertainty about the impact of other factors. We therefore echo that review's call for more research to be done on this topic.

The studies identified in our systematic review generally focused on epidemiology in specific regions and disease groups, meaning that extrapolation to the international community could be difficult. Collection of data from patient registries or chart reviews from specialist centers would help to clarify the size of the problem, whether there are regional differences in the risk of LLS for each underlying condition, and how the epidemiology of LLS is changing over time.

The existing published evidence suggests that the severity of LLS seems to vary according to the underlying pathology. The limited data available suggest that most patients with stroke have mild spasticity, 3,6,12,13 but that the severity of spasticity is likely to be much higher in cerebral palsy ${ }^{21}$ and multiple sclerosis. ${ }^{14,16-18}$ One study showed that spasticity is associated with pain, especially in patients with cerebral palsy, ${ }^{21}$ and suggests a substantial quality of life burden from LLS that needs be explored further.

The complications and impact of LLS are far from certain. There is little reason to doubt that LLS limits mobility regardless of the underlying cause $\mathrm{e}^{15,17,23}$ and, therefore, that it has an adverse effect on independence and quality of life among patients and increases the burden on carers. However, there seems to be some evidence that spasticity itself may not be a cause of contractures around affected joints, ${ }^{19,25-27}$ and unclear evidence as to whether or not LLS increases the likelihood of falling. ${ }^{13,22}$ One study of particular interest found a much higher incidence of deep vein thrombosis in the affected leg of patients with spasticity. ${ }^{28}$ Current prophylaxis and treatment of deep vein thrombosis focuses on systemic anticoagulation, and this approach obviously carries key bleeding risks in elderly and infirm patients, especially after a hemorrhagic stroke. ${ }^{38}$

The economic burden of LLS is unknown. The limited data we found in this regard (one study) focused on comparison of the costs of two formulations of botulinum toxin type A. ${ }^{29}$ As this was not a randomized controlled trial, and there were substantial differences in the underlying diseases predisposing to the type of LLS being treated with the two formulations, no useful economic conclusions can be drawn from it. Again, further database or chart review studies on resources used for patients with LLS affecting different muscle groups and with different underlying pathologies could help clinicians and payers to better understand the potential economic implications of this condition and its treatment.

\section{Evidence gaps}

Our literature review found limited evidence on the burden of illness associated with LLS. This is in part because we focused on studies published in the past 10 years, to ensure that the review reflected current disease epidemiology and management. Further, we restricted our search to studies that specifically discussed LLS rather than spasticity of any muscle group. These are thus limitations to our systematic review. Substantial gaps in the present study need to be addressed to determine the prevalence and incidence of LLS, the condition's humanistic (eg, quality of life) burden on patients and their carers, and the economic burden associated with LLS and its management. In particular, we did not identify any articles published in the last 10 years that had reported on the incidence of LLS, trends in the incidence or prevalence of LLS over time or across different geographical regions, the natural progression of LLS and its complications, treatment satisfaction among LLS patients, the burden on carers of LLS patients, access to care and unmet needs of LLS patients, or costs of illness associated with LLS.

\section{Conclusion}

The lack of robust data on the epidemiology and impact of adult LLS, patient-reported outcomes, and possible complications of LLS means that we cannot be sure of the overall burden of LLS in terms of morbidity, mortality, and quality of life. However, there are indications that a substantial proportion of adults with stroke, multiple sclerosis, cerebral palsy and other motor neuron disorders may have LLS, and that this may sometimes go unrecognized by health care professionals. We also found no substantive data on the economic burden of LLS, the level of unmet need related to treatment and support for patients or carers, or how the burden might be eased by widespread use of effective interventions. Further research on these areas is necessary to guide clinicians, payers, and patients on benefits that might arise from a greater understanding of the problem and its effective management. 


\section{Acknowledgments}

The authors would like to acknowledge the following contributors to this article: Ike Iheanacho, who provided editorial input, and Louise Lombard, Amy McDonough, and Erica Zaiser, who contributed to data collection and analysis.

\section{Disclosure}

AM and SA are both employed by Evidera. HK and JD are employees of Ipsen. The authors report no other conflicts of interest in this work. Funding of this literature review was provided by Ipsen Pharma SAS.

\section{References}

1. O'Brien CF. Treatment of spasticity with botulinum toxin. Clin J Pain. 2002;18(Suppl 6):S182-S190.

2. Ward AB. A literature review of the pathophysiology and onset of post-stroke spasticity. Eur J Neurol. 2012;19(1):21-27.

3. Leathley MJ, Gregson JM, Moore AP, Smith TL, Sharma AK, Watkins CL. Predicting spasticity after stroke in those surviving to 12 months. Clin Rehabil. 2004;18(4):438-443.

4. Lundstrom E, Smits A, Terent A, Borg J. Time-course and determinants of spasticity during the first six months following first-ever stroke. J Rehabil Med. 2010;42(4):296-301.

5. Lundstrom E, Terent A, Borg J. Prevalence of disabling spasticity 1 year after first-ever stroke. Eur J Neurol. 2008;15(6):533-539.

6. Urban PP, Wolf T, Uebele M, et al. Occurence and clinical predictors of spasticity after ischemic stroke. Stroke. 2010;41(9):2016-2020.

7. Welmer AK, Widen Holmqvist L, Sommerfeld DK. Location and severity of spasticity in the first $1-2$ weeks and at 3 and 18 months after stroke. Eur J Neurol. 2010;17(5):720-725.

8. Schinwelski M, Slawek J. Prevalence of spasticity following stroke and its impact on quality of life with emphasis on disability in activities of daily living. Systematic review. Neurol Neurochir Pol. 2010;44(4): 404-411.

9. Bohannon RW, Smith MB. Interrater reliability of a modified Ashworth Scale of muscle spasticity. Phys Ther. 1987;67:206-207.

10. Ashworth B. Preliminary trial of carisoprodol in multiple sclerosis. Practitioner. 1964;192:540-542.

11. Tardieu G, Shentoub S, Delarue R. A la recherché d'une technique de mesure de la spasticite. [Research on a technique for measurement of spasticity]. Rev Neurol. 1954;91:143-144. French.

12. Dajpratham P, Kuptniratsaikul V, Kovindha A, Kuptniratsaikul PS, Dejnuntarat K. Prevalence and management of poststroke spasticity in Thai stroke patients: a multicenter study. J Med Assoc Thai. 2009;92(10):1354-1360.

13. Soyuer F, Ozturk A. The effect of spasticity, sense and walking aids in falls of people after chronic stroke. Disabil Rehabil. 2007;29(9): 679-687.

14. Hoang P, Herbert R, Gandevia S. Prevalence of joint contractures, muscle weakness, and spasticity in multiple sclerosis. Neurorehabil Neural Repair. 2012;26(6):661-662.

15. Marcotte TD, Rosenthal TJ, Roberts E, et al. The contribution of cognition and spasticity to driving performance in multiple sclerosis. Arch Phys Med Rehabil. 2008;89(9):1753-1758.

16. Salci Y, Aydonullan S, Fil A, et al. Investigation of musculoskeletal pain in Turkish multiple sclerosis population. Neurorehabil Neural Repair. 2012;26(6):710.

17. Sosnoff JJ, Gappmaier E, Frame A, Motl RW. Influence of spasticity on mobility and balance in persons with multiple sclerosis. J Neurol Phys Ther. 2011;35(3):129-132.

18. Wagner JM, Kremer TR. Relationships between ankle spasticity and strength, walking capacity and self-perceived walking limitations in multiple sclerosis. Arch Phys Med Rehabil. 2012;93(10):E17.
19. Singer BJ, Jegasothy GM, Singer KP, Allison GT, Dunne JW. Incidence of ankle contracture after moderate to severe acquired brain injury. Arch Phys Med Rehabil. 2004;85(9):1465-1469.

20. Singer MA, Kojan S, Barohn RJ, et al. Primary lateral sclerosis: Clinical and laboratory features in 25 patients. J Clin Neuromuscul Dis. 2005;7(1):1-9.

21. Noonan KJ, Jones J, Pierson J, Honkamp NJ, Leverson G. Hip function in adults with severe cerebral palsy. J Bone Joint Surg Am. 2004; 86-A(12):2607-2613.

22. Marciniak CM, Beltran EJ, Dudas-Sheehan D, et al. Why do individuals with cerebral palsy stop ambulating? Physical Medicine and Rehabilitation. 2011;3(10):S300.

23. Pang MY, Eng JJ. Fall-related self-efficacy, not balance and mobility performance, is related to accidental falls in chronic stroke survivors with low bone mineral density. Osteoporos Int. 2008;19(7):919-927.

24. Voerman GE, Erren-Wolters CV, Fleuren JF, Hermens HJ, Geurts AC. Perceived spasticity in chronic spinal cord injured patients: associations with psychological factors. Disabil Rehabil. 2010;32(9):775-780.

25. Diong J, Harvey LA, Kwah LK, et al. Incidence and predictors of contracture after spinal cord injury - a prospective cohort study. Spinal Cord. 2012;50(8):579-584.

26. Kwah LK, Harvey LA, Diong JH, Herbert RD. Half of the adults who present to hospital with stroke develop at least one contracture within six months: an observational study. J Physiother. 2012;58(1):41-47.

27. Laurent G, Valentini F, Loiseau K, Hennebelle D, Robain G. Claw toes in hemiplegic patients after stroke. Ann Phys Rehabil Med. 2010;53(2): $77-85$.

28. Hara Y. Deep venous thrombosis in stroke patients during rehabilitation phase. Keio J Med. 2008;57(4):196-204.

29. Burbaud P, Ducerf C, Cugy E, et al. Botulinum toxin treatment in neurological practice: how much does it really cost? A prospective cost-effectiveness study. J Neurol. 2011;258(9):1670-1675.

30. Esquenazi A, Mayer N, Lee S, et al. Patient registry of outcomes in spasticity care. Am J Phys Med Rehabil. 2012;91(9):729-746.

31. Marchese D, Hubert C, Mendoza J, Schwab J, Zakine B. Adult lower limb spasticity treatment in the European Union: botulinum toxin type a (Dysport) dosing and reconstitution techniques. Physical Medicine and Rehabilitation. 2010;2(9):S149.

32. Zamli A, Xiong X. Experience with immediate effect of electrical nerve stimulation guided botulinum toxin type a injection for adult spasticity. Neurorehabil Neural Repair. 2012;26(6):717.

33. Nogueira LA, Nobrega FR, Lopes KN, Thuler LC, Alvarenga RM. The effect of functional limitations and fatigue on the quality of life in people with multiple sclerosis. Arq Neuropsiquiatr. 2009;67(3B): 812-817.

34. Feigin VL, Lawes CM, Bennett DA, Anderson CS. Stroke epidemiology: a review of population-based studies of incidence, prevalence, and casefatality in the late 20th century. Lancet Neurol. 2003;2(1):43-53.

35. Truelsen T, Piechowski-Jozwiak B, Bonita R, Mathers C, Bogousslavsky J, Boysen G. Stroke incidence and prevalence in Europe: a review of available data. Eur J Neurol. 2006;13(6):581-598.

36. Cripps RA, Lee BB, Wing P, Weerts E, Mackay J, Brown D. A global map for traumatic spinal cord injury epidemiology: towards a living data repository for injury prevention. Spinal Cord. 2011;49(4): 493-501.

37. Devivo MJ. Epidemiology of traumatic spinal cord injury: trends and future implications. Spinal Cord. 2012;50(5):365-372.

38. Tulner LR, Kuper IM, van Campen JP, et al. Contraindications for anticoagulation in older patients with atrial fibrillation; a narrative review. Curr Drug Saf. 2010;5(3):223-233.

39. Benamer HT, Grosset D. Stroke in Arab countries: a systematic literature review. J Neurol Sci. 2009;284(1-2):18-23.

40. Saposnik G, Del Brutto OH; Iberoamerican Society of Cerebrovascular Diseases. Stroke in South America: a systematic review of incidence, prevalence, and stroke subtypes. Stroke. 2003;34(9):2103-2107.

41. Hirtz D, Thurman DJ, Gwinn-Hardy K, Mohamed M, Chaudhuri AR, Zalutsky R. How common are the "common" neurologic disorders? Neurology. 2007;68(5):326-337. 
42. Burke TA, Venketasubramanian RN. The epidemiology of stroke in the East Asian region: a literature-based review. Int J Stroke. 2006;1(4): 208-215.

43. Cristiano E, Patrucco L, Rojas JI. A systematic review of the epidemiology of multiple sclerosis in South America. Eur J Neurol. 2008;15(12): 1273-1278.

44. Cooper GS, Bynum ML, Somers EC. Recent insights in the epidemiology of autoimmune diseases: improved prevalence estimates and understanding of clustering of diseases. J Autoimmun. 2009;33(3-4): 197-207.

45. Poppe AY, Wolfson C, Zhu B. Prevalence of multiple sclerosis in Canada: a systematic review. Can J Neurol Sci. 2008;35(5): 593-601.
46. Yeargin-Allsopp M, Van Naarden Braun K, Doernberg NS, Benedict RE, Kirby RS, Durkin MS. Prevalence of cerebral palsy in 8-year-old children in three areas of the United States in 2002: a multisite collaboration. Pediatrics. 2008;121(3):547-554.

47. Tagliaferri F, Compagnone C, Korsic M, Servadei F, Kraus J. A systematic review of brain injury epidemiology in Europe. Acta Neurochir (Wien). 2006;148(3):255-268.

48. Hagen EM, Rekand T, Gilhus NE, Gronning M. Traumatic spinal cord injuries - incidence, mechanisms and course. Tidsskr Nor Laegeforen. 2012;132(7):831-837.

49. Wyndaele M, Wyndaele JJ. Incidence, prevalence and epidemiology of spinal cord injury: what learns a worldwide literature survey? Spinal Cord. 2006;44(9):523-529. 


\section{Supplementary materials \\ Search strategy \\ Database searches}

Gray literature search

We searched the gray literature (material that can be referenced but is not published in peer-reviewed, MEDLINEindexed, or EMBASE-indexed medical journals) for any information pertaining to epidemiologic, quality of life, and economic outcomes of the burden of LLS. We manually searched the following websites for articles relevant to LLS, using the same inclusion criteria as for the database searches:

- World Federation for Neurorehabilitation (http://wfnr. co.uk)

- World Stroke Congress (http://www1.kenes.com/ $\underline{\mathrm{WSC}})$

- World Federation of Neurology (http://www.wfneurology. org)

- American Neurological Association/Association of British Neurologists (http://www.aneuroa.org)

\section{Inclusion and exclusion criteria}

\section{Inclusion criteria}

Patient population

- Patients older than 18 years of age with LLS, that could have resulted from any of the following underlying diseases:

o Stroke o Multiple sclerosis

o Traumatic brain injury

o Cerebral palsy

o Others, for example, Parkinson's disease

- Studies reporting follow-up from childhood to adulthood

- Studies with more than $50 \%$ adult populations

Outcomes

- Epidemiologic outcomes

o Prevalence and incidence of LLS due to different underlying pathologies, as listed above under population

o Trends of LLS over time

o Outcomes and prognosis of LLS

o Health and social problems associated with LLS

o Comorbidities associated with LLS

o Treatment patterns with botulinum toxin or other interventions in adults with LLS

- Humanistic/quality of life outcomes

o Utilities associated with LLS

o Quality of life outcomes with LLS

o Patient-reported outcomes

o Patient satisfaction with treatment/care for LLS

o Burden on carers of patients with LLS

o Quality of life associated with efficacy/effectiveness of treatment for LLS

o Access to care

o Unmet needs

Table SI Search string for MEDLINE-indexed publications

\begin{tabular}{|c|c|c|}
\hline & Search algorithm & Hits \\
\hline I. Quality of life string & $\begin{array}{l}\text { ("quality of life"[tiab] OR “quality-of-life"[tiab] OR “patient reported outcome"[tiab] OR "patient-reported } \\
\text { outcome"[tiab] OR "patient reported outcomes"[tiab] OR "patient-reported outcomes"[tiab] OR } \\
\text { satisfaction[tiab] OR utility[tiab] OR disability[tiab] OR "functional status"[tiab] OR "physical function"[tiab] OR } \\
\text { burden[tiab] OR carer[tiab] OR pain[tiab] OR mobility[tiab] OR 'self care'[tiab] OR hygiene[tiab] OR falls[tiab]) }\end{array}$ & 326,689 \\
\hline 2. Economic string & $\begin{array}{l}\text { (Cost[MeSH] OR economic[MeSH] OR "burden of illness"[tiab] OR "illness burden”[tiab] OR } \\
\text { "cost benefit"[tiab] OR "cost-benefit"[tiab] OR "cost-effective"[tiab] OR "cost effective"[tiab] OR } \\
\text { expenditure[MeSH] OR "quality-adjusted life year"[tiab] OR "quality adjusted life year"[tiab] OR qaly[tiab] } \\
\text { OR "life years saved"[tiab] OR deductible[tiab] OR insurance[tiab] OR "value of life"[tiab] OR budget[MeSH] } \\
\text { OR fiscal[tiab] OR funding[tiab] OR financial[tiab] OR finance[tiab] OR price[tiab] OR pricing[tiab]) }\end{array}$ & 110,282 \\
\hline 3. Epidemiologic string & $\begin{array}{l}\text { (Incidence[tiab] OR prevalence[tiab] OR incidence[MeSH] OR prevalence[MeSH] OR epidemiology[MeSH] } \\
\text { OR “epidemiological data"[tiab] OR epidemiology[tiab] OR epidemiologic[tiab] OR epidemiological[tiab] } \\
\text { OR "unmet need"[tiab] OR access[tiab]) }\end{array}$ & $4 \mid 4,403$ \\
\hline 4. & I OR 2 OR 3 & 753,166 \\
\hline 5. Disease string & $\begin{array}{l}\text { ((spasticity[tiab] OR palsy[tiab] OR rigidity[tiab] OR hemiparesis[tiab] OR hemiplegia[tiab] OR "brain } \\
\text { injury"[tiab] OR stroke[tiab] OR “multiple sclerosis"[tiab] OR hypertonic*[tiab] OR "cerebral palsy"[tiab] } \\
\text { OR botulinum[tiab]) AND (leg[tiab] OR “lower limb"[tiab] OR calf[tiab] OR thigh[tiab] OR knee[tiab] } \\
\text { OR foot[tiab] OR ankle[tiab] OR hip[tiab])) }\end{array}$ & 3,951 \\
\hline 6. & 4 AND 5 & $\mathrm{I}, 457$ \\
\hline 7. & NOT (child NOT (adult AND child)) & 1,326 \\
\hline 8. & $\begin{array}{l}\text { NOT (Review[pt] NOT (systematic[tiab] OR "meta analysis" [tiab] OR (indirect[tiab] } \\
\text { OR mixed[tiab] AND "treatment comparison"[tiab]))) }\end{array}$ & 1,188 \\
\hline
\end{tabular}

Note: The limits for the MEDLINE search were: only items with abstracts, humans, published in the last 10 years (October 2002 to October 20I2) and field: Title/Abstract. 
Table S2 Search string for EMBASE-indexed publications

\begin{tabular}{|c|c|c|}
\hline & Search algorithm & Hits \\
\hline I. Quality of life string & $\begin{array}{l}\text { ('quality of life':ab,ti OR ‘quality-of-life':ab,ti OR ‘patient reported outcome':ab,ti OR ‘patient- } \\
\text { reported outcome':ab,ti OR 'patient reported outcomes':ab,ti OR 'patient-reported outcomes':ab,ti } \\
\text { OR 'satisfaction':ab,ti OR 'utility':ab,ti OR ‘disability':ab,ti OR 'functional status':ab,ti OR ‘physical } \\
\text { function':ab,ti OR burden:ab,ti OR carer:ab,ti OR pain:ab,ti OR mobility:ab,ti OR ‘self care':ab,ti } \\
\text { OR hygiene:ab,ti OR falls:ab,ti) }\end{array}$ & 388,882 \\
\hline 2. Economic string & $\begin{array}{l}\text { ('cost'/exp OR economic OR 'burden of illness':ab,ti OR 'illness burden':ab,ti OR 'cost benefit':ab,ti } \\
\text { OR 'cost-benefit':ab,ti OR 'cost-effective':ab,ti OR 'cost effective':ab,ti OR expenditure OR } \\
\text { 'quality-adjusted life years':ab,ti OR 'quality adjusted life years':ab,ti OR qaly:ab,ti OR 'life years } \\
\text { saved':ab,ti OR deductible:ab,ti OR insurance:ab,ti OR 'value of life':ab,ti OR ‘budget'/exp OR } \\
\text { fiscal:ab,ti OR funding:ab,ti OR financial:ab,ti OR finance:ab,ti OR price OR pricing:ab,ti) }\end{array}$ & 221,870 \\
\hline 3. Epidemiologic string & $\begin{array}{l}\text { ('incidence'/exp OR ‘prevalence'/exp OR ‘epidemiology'/exp OR morbidity:ab,ti } \\
\text { OR mortality:ab,ti OR survival:ab,ti OR 'unmet need'ab,ti OR access:ab,ti) }\end{array}$ & 835,121 \\
\hline 4. & I OR 2 OR 3 & $|2,235,93|$ \\
\hline 5. Disease string & $\begin{array}{l}\text { ((spasticity:ab,ti OR palsy:ab,ti OR rigidity:ab,ti OR hemiparesis:ab,ti OR hemiplegia:ab,ti OR } \\
\text { “brain injury”:ab,ti OR stroke:ab,ti OR “multiple sclerosis”:ab,ti OR hypertonic*:ab,ti OR “cerebral } \\
\text { palsy”:ab,ti OR botulinum:ab,ti) AND (leg:ab,ti OR “lower limb”:ab,ti OR calf:ab,ti OR thigh:ab,ti OR } \\
\text { knee:ab,ti OR foot:ab,ti OR ankle:ab,ti OR hip:ab,ti)) }\end{array}$ & 6,026 \\
\hline 6. & 4 AND 5 & 2,674 \\
\hline 7. & NOT (child NOT (adult AND child)) & 2,352 \\
\hline 8. & $\begin{array}{l}\text { NOT (Review[pt] NOT systematic:ab,ti OR “meta analysis”:ab,ti OR indirect:ab,ti OR mixed:ab,ti } \\
\text { AND “treatment comparison”:ab,ti) }\end{array}$ & 1,918 \\
\hline
\end{tabular}

Note: The limits for the EMBASE search were: only items with abstracts, humans, published in the last 10 years (October 2002 to October 2012$)$ and field: Title/Abstract.

- Economic outcomes

o Direct costs of LLS (health and social care)

o Indirect costs of LLS (eg, productivity, employment for patients and carers)

o Resource use by patients with LLS and carers, including costs and resource use associated with treatments for LLS (pharmacological or non-pharmacological)

o Burden on society from LLS

Year of publication

- Studies published in the last 10 years (2002-2012)

Languages

- Only publications in English were considered

Study design

- Primary research including cohort studies, case-control studies, cross-sectional studies, case series, and randomized controlled trials (if available), and database studies

\section{Exclusion criteria}

Patient population

- Studies investigating patients without LLS

- Studies on adolescents and children younger than 18 years of age with LLS

Outcomes

- Articles without relevant data on any of the outcomes of interest
- Studies on genetic profiling

- Prevalence studies with fewer than ten participants

- Articles investigating the efficacy and/or effectiveness of botulinum toxin or any other investigation in the treatment of LLS

- Studies investigating the biomechanical factors associated with spasticity (eg, electromyogram findings, joint angle, foot position, muscle blood flow)

- Studies assessing the validity of instruments used to measure spasticity

Study design

- Letters to the editor

- Narrative reviews

- Editorials

- Expert opinions

- Case studies

Articles were not excluded based on the geographic location. Systematic review articles published in the past four years (October 2008-October 2012) and meeting abstracts from the last two years or last two conference meetings were also included.

Abbreviation: LLS, lower limb spasticity. 


\section{Publish your work in this journal}

Neuropsychiatric Disease and Treatment is an international, peerreviewed journal of clinical therapeutics and pharmacology focusing on concise rapid reporting of clinical or pre-clinical studies on a range of neuropsychiatric and neurological disorders. This journal is indexed on PubMed Central, the 'PsycINFO' database and CAS.

The manuscript management system is completely online and includes a very quick and fair peer-review system, which is all easy to use. Visit http://www.dovepress.com/testimonials.php to read real quotes from published authors.

\footnotetext{
Submit your manuscript here: http://www.dovepress.com/neuropsychiatric-disease-and-treatment-journal
} 